\title{
Concurrent chemoradiotherapy for stage III non-small-cell lung cancer: recent progress and future perspectives (a narrative review)
}

\author{
Małgorzata Łazar-Poniatowska, Artur Bandura, Rafał Dziadziuszko, Jacek Jassem \\ Department of Oncology and Radiotherapy, Medical University of Gdańsk, Gdańsk, Poland \\ Contributions: (I) Conception and design: All authors; (II) Administrative support: All authors; (III) Provision of study materials or patients: All \\ authors; (IV) Collection and assembly of data: All authors; (V) Data analysis and interpretation: All authors; (VI) Manuscript writing: All authors; (VII) \\ Final approval of manuscript: All authors. \\ Correspondence to: Małgorzata Łazar-Poniatowska. Department of Oncology and Radiotherapy, Medical University of Gdańsk, 17 Smoluchowskiego \\ St., 80-214 Gdańsk, Poland. Email: poniatowska@gumed.edu.pl.
}

\begin{abstract}
Concurrent chemoradiotherapy (CHRT) remains the therapeutic standard for locally advanced inoperable non-small-cell lung cancer (NSCLC). The median overall survival (OS) with this approach is in the range of 20-30 months, with five-year survival of approximately $30 \%$. These outcomes have recently been further improved by supplementing CHRT with maintenance durvalumab, a monoclonal anti-PD-L1 agent. The progress in treatment outcomes of locally advanced NSCLC before the era of immunotherapy has been achieved mainly by virtue of developments in diagnostics and radiotherapy techniques. Routine implementation of endoscopic and endobronchial ultrasonography for mediastinal lymph nodes assessment, positron emission tomography/computed tomography and magnetic resonance imaging of the brain allows for more accurate staging of NSCLC and for optimizing treatment strategy. Thorough staging and respiratory motion control allows for higher conformity of radiotherapy and reduction of radiotherapy related toxicity. Dose escalation with prolonged overall treatment time does not improve treatment outcomes of CHRT. In consequence, 60 Gy in 2 Gy fractions or equivalent biological dose remains the standard dose for definitive CHRT in locally advanced NSCLC. However, owing to increased toxicity of CHRT, this option may not be applicable in a proportion of elderly or frail patients. This article summarizes recent developments in curative CHRT for inoperable stage III NSCLC, and presents perspectives for further improvements of this strategy
\end{abstract}

Keywords: Stage III non-small-cell lung cancer (stage III NSCLC); concomitant chemoradiotherapy; chemotherapy; radiotherapy

Submitted May 29, 2020. Accepted for publication Nov 05, 2020.

doi: $10.21037 /$ tlcr-20-704

View this article at: http://dx.doi.org/10.21037/tlcr-20-704

\section{Introduction}

Recent advances in the diagnosis and staging of nonsmall-cell lung cancer (NSCLC) have led to more precise characterization of stage III disease. Current 8th TNM staging classification recognizes stage III NSCLC as three different groups: IIIA, IIIB and IIIC (1). These categories differ substantially in terms of treatment options and outcomes, but in all instances curative approaches usually include multimodality treatment consisting of radiotherapy (RT) and/or surgery combined with chemotherapy (CHT) (2). Whereas surgical options are frequently attempted for patients with stage IIIA, the remaining two groups are typically managed with RT, in most cases combined with sequential or concomitant CHT. Several clinical studies and meta-analyses have documented concomitant chemoradiotherapy (CHRT) as the most effective definitive 
treatment in locally advanced inoperable NSCLC, and this strategy constitutes the current standard in this setting. The median overall survival (OS) with CHRT in clinical trials performed in the past decade was in the range of 20-30 months, with five-year OS of approximately $30 \%$ (Table 1) (3-10). The recent PACIFIC study demonstrated that these outcomes may be considerably improved with the addition of maintenance durvalumab, a monoclonal anti-PD-L1 agent (10) (RT-immunotherapy combinations are addressed in another article of this issue). Recent progress in treatment outcomes of locally advanced NSCLC has been achieved mainly by improvements in diagnostic and staging tools and advanced RT techniques. This article will summarize these developments and provide the rationale for further efforts to increase locoregional control and OS with CHRT. We present the following article in accordance with the Narrative Review reporting checklist (available at http://dx.doi. org/10.21037/tlcr-20-704).

\section{Methods}

Literature searches of the MEDLINE ${ }^{\circledR}$ and PubMed ${ }^{\circledR}$ databases were carried out to identify journal articles published before May 2020. The following key words were used and combined to search the databases: 'stage III lung cancer', 'stage III NSCLC', 'chemoradiotherapy', 'chemoradiation'. Publications detailing phase II or III studies, retrospective analyses and meta-analyses relevant to reviewed topic were identified.

\section{Improvements in diagnosis and staging}

Patients who are histologically or cytologically diagnosed with lung cancer should undergo a quick, yet thorough staging. Approximately one-third of NSCLC patients present with stage III disease (2) and are candidates for various multimodality approaches. Within the past two decades several important diagnostic tools have been largely implemented in NSCLC. These include mediastinal staging with ultrasound-guided transbronchial or transesophageal needle aspiration biopsy (EBUS and EUS TBNA, respectively), which largely replaced mediastinoscopy, computed tomography (CT), magnetic resonance (MR) of the brain, and 18-fluoro-D-glucose positron emission tomography coupled with computed tomography $\left({ }^{18} \mathrm{~F}-\mathrm{FDG}\right.$ PET-CT). Other staging procedures are employed depending on particular symptoms or findings. For example, video thoracoscopy is performed in patients with pleural effusion, and chest MR in those with chest wall or spine invasion. More accurate anatomical information on the tumor extent results in upstaging of presumed stage III in a substantial proportion of patients, and allows for more precise treatment delivery. The degree by which these diagnostic developments might have influenced the outcomes of concurrent CHRT is summarized below.

\section{${ }^{18}$ F-FDG PET-CT}

Within the past decade, ${ }^{18} \mathrm{~F}-\mathrm{FDG}$ PET-CT for lung cancer staging and RT planning has been implemented in most institutions, and is currently a part of international guidelines $(11,12)$. Examples of particular usefulness of this diagnostic tool in accurate delineation of primary tumor extent are post-obstructive atelectasis or chest wall invasion (13). ${ }^{18} \mathrm{~F}$-FDG PET-CT is also more accurate than conventional CT in the assessment of mediastinal lymph nodes. The meta-analysis of 39 studies demonstrated that the median sensitivity and specificity of ${ }^{18} \mathrm{~F}-\mathrm{FDG}$ PET-CT for the detection of lymph node involvement was $85 \%$ and $90 \%$, respectively, compared with $61 \%$ and $79 \%$, respectively, for CT alone (14). In the recent PET-Plan phase III trial, stage III NSCLC patients were allocated to definitive CHRT to target volume delineation informed by ${ }^{18} \mathrm{~F}$-FDG PET-CT with or without elective nodal irradiation (ENI) (15). Isotoxic dose escalation was allowed from 60 to $74 \mathrm{~Gy}$, with 2 Gy per fraction. The cumulative incidence of locoregional progression at one year was more than two-fold lower in the latter group [per protocol analysis, $14 \%$ (95\% CI: $5-21 \%$ ) vs. $29 \%$ (95\% CI: $17-38 \%)$; HR $=0.57$ (95\% CI: 0.30-1.06)], respectively, with similar risk of out-of-field recurrence (below $10 \%$ in both arms). Thus, RT planning based on ${ }^{18}$ F-FDG PETCT, with omission of PET-negative lymph nodes, may be considered a current standard of care. A note of caution, however, should be made for PET-CT negative or enlarged lymph nodes (more than $10 \mathrm{~mm}$ in short axis), which should always be subjected to pathological staging with EBUS, EUS or mediastinoscopy, depending on their location.

${ }^{18}$ F-FDG PET-CT has a well-proven value for the detection of asymptomatic distant metastases. In stage III NSCLC, after ${ }^{18}$ F-FDG PET approximately $20-30 \%$ of patients are upstaged to stage $\mathrm{IV}$, and this procedure is the main cause of stage migration. A prospective two-cohort study including stage III NSCLC patients considered for neoadjuvant CHRT followed by surgery demonstrated 


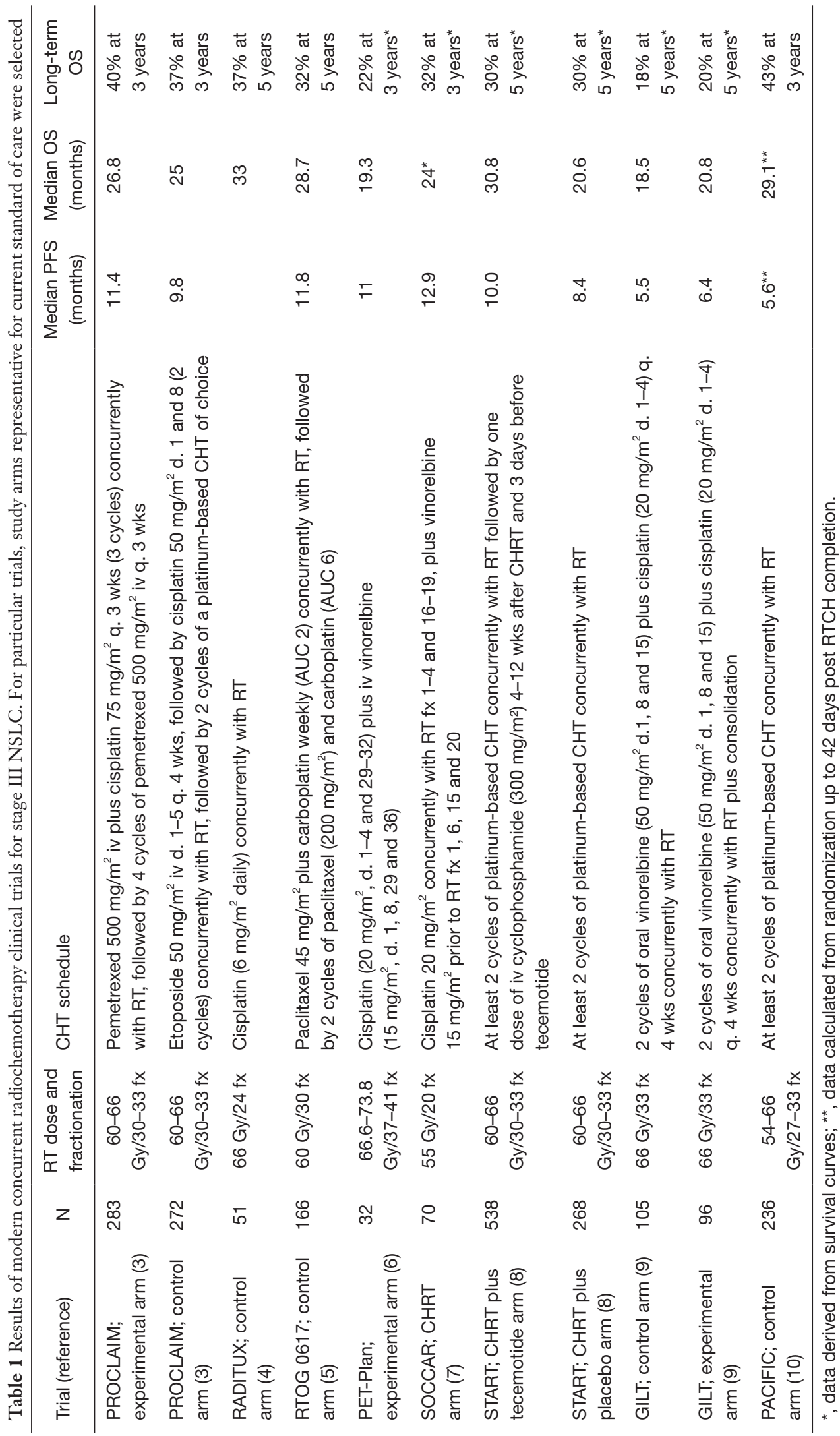


that out of 115 patients who underwent ${ }^{18} \mathrm{~F}-\mathrm{FDG}$ PET, $28(24 \%)$ were excluded from planned therapy due to upstaging to stage IV. Stage migration in this group resulted in improved outcomes compared to subjects who did not undergo ${ }^{18}$ F-FDG PET (median OS of 22.3 and 11.3 months, respectively). A meta-analysis including studies of concurrent CHRT performed between 1988 and 2003 , i.e., before the routine introduction of ${ }^{18} \mathrm{~F}-\mathrm{FDG}$ PET and ${ }^{18}$ F-FDG PET-CT, showed a median OS of 18 months in stage III NSCLC (16). With the assumption of $20 \%$ to $30 \%$ upstaging to metastatic NSCLC by routine ${ }^{18}$ F-FDG PET imaging, and a 12 -month median OS in stage $\mathrm{IV}$, the estimated median OS of true stage III patients (PET negative for distant metastases) is in the range of 19.5 to 20.3 months. These values are still in a lower range of recent studies using concurrent CHRT (Table 1). For example, in the PROCLAIM trial comparing two CHT regimens combined with concurrent RT in stage III NSCLC, the post-hoc analysis showed the median OS of 27.2 and 20.8 months, respectively, in patients who did and did not undergo initial ${ }^{18} \mathrm{~F}$-FDG PET-CT imaging (HR $=0.81 ; \mathrm{P}=0.13)(17)$.

\section{Brain imaging}

The incidence of asymptomatic brain metastases at presentation in stage III NSCLC ranges between $10 \%$ and $20 \%$, and is relatively common in lung adenocarcinoma $(18,19)$. Improved survival of locally advanced NSCLC by virtue of modern therapeutic approaches increases the risk of overt brain relapse. Currently, most specialized centers routinely perform brain imaging as a part of initial staging in patients considered for curative approaches. Since ${ }^{18}$ F-FDG PET-CT has low diagnostic accuracy for brain metastases, routine brain imaging includes CT or MRI; the latter identifying additional $4.7 \%$ of patients with brain dissemination compared to CT (20).

\section{Invasive mediastinal lymph node staging}

Although ${ }^{18}$ F-FDG PET-CT has greatly improved the diagnosis of hilar and mediastinal lymph node involvement in NSCLC, a proportion of stage III patients will need invasive staging of mediastinal lymph nodes. Indeed, the specificity of ${ }^{18}$ F-FDG PET-CT in mediastinal lymph node assessment ranges from $80 \%$ to $90 \%$, with false-positive findings resulting mostly from coexisting inflammatory diseases such as sarcoidosis, anthracosis or tuberculosis.
Thus, EBUS and/or EUS TBNA, or mediastinoscopy are routinely used in these patients to exclude non-cancerous causes of ${ }^{18}$ F-FDG PET-CT positivity. More controversial is the use of EBUS/EUS TBNA prior to definitive CHRT in patients with ${ }^{18} \mathrm{~F}$-FDG PET-CT negative lymph nodes. In cases with CT-enlarged (short axis above $10 \mathrm{~mm}$ ) vs. normal lymph nodes, these invasive procedures decrease the risk of false-negative reading of ${ }^{18} \mathrm{~F}$-FDG PET-CT by $10 \%$ and $5 \%$, respectively (21). Such upstaging results in encompassing additional lymph node groups in RT planning, with presumed reduction of geographical miss. However, the real impact of invasive mediastinal staging in addition to ${ }^{18} \mathrm{~F}$-FDG PET-CT on long-term outcomes in stage III NSCLC patients managed with CHRT is not well established.

\section{Tumor volume and its dynamics}

Currently, treatment strategy in locally advanced NSCLC is mainly based on tumor advancement and standard patient features, such as performance status and comorbidities. Novel high-precision technologies assessing tumor volume and its dynamics during RT may inform personalized treatment decisions. Examples of such opportunities are discussed below.

One of the basic assumptions in radiobiology is that the number of potential stem cells which must be sterilized is proportional to the tumor volume, and strongly affects the dose required to control the tumor (22). This implies consideration of dose corrections according to tumor size. Indeed, larger gross tumor volume (GTV) is associated with lower potential of cure and higher probability of distant metastases $(23,24)$. Most of the dichotomous analyses using GTV cut-offs ranging from 45 to $200 \mathrm{~cm}^{3}$ demonstrated strong prognostic impact of this measure (25). In the study of Bradley et al. (26), GTV was more predictive for OS than $\mathrm{T}$ category, $\mathrm{N}$ category and clinical stage. In a prospective TROG 99.05 trial, larger primary tumor was prognostic of death during the first 18 months, but not beyond (27). In another study, continuous increase of initial GTV (by $10 \mathrm{~cm}^{3}$ ) impacted OS in univariate analysis, but in multivariate analysis this association was significant only in adenocarcinomas (28). Bradley et al. (26) hypothesized that the dose above 70 Gy may lead to improved cause-specific survival. This hypothesis was prospectively evaluated in the RTOG 0617 study discussed later in this review.

Currently, delineation of GTV in locally advanced NSCLC patients managed with definitive CHRT is 
mostly based on ${ }^{18}$ F-FDG PET-CT. Hence, pretreatment volume of metabolically active tumor (MTV) may serve as prognostic factor and inform treatment modifications (29). In the study of Ohri et al. (30) median OS for patients with MTV below and above $95.4 \mathrm{~cm}^{3}$ (determined as the optimal cutoff value) was 23.6 and 13.4 months, respectively (log-rank $\mathrm{P}<0.001)$. Median OS for those in the lowest, middle and highest tertile of MTV was 29.7, 21.2 and 13.6 months, respectively $(\mathrm{P}<0.001)$. In this study, MTV was also indicative for local control. In another study, two-year cumulative incidence rate of in-field progression for lesions below and above $25 \mathrm{~cm}^{3}$ was $5 \%$ and $45 \%$, respectively $(\mathrm{P}<0.001)$ (31). Pretreatment maximum ${ }^{18} \mathrm{~F}$-FDG PET-CT standardized uptake value (SUVmax) of the primary tumor is associated with the probability of complete remission (32). In the study of Lee et al. (33) nodal SUVmax of less than 8 was correlated with improved PFS, distant metastasisfree survival and OS. Complex associations between PET findings and prognosis of NSCLC are discussed in the recent review of Brodin et al. 2020 (29).

A new therapeutic approach in locally advanced NSCLC is adaptive RT, employing temporal changes in the treatment plan delivered to the patient, according to anatomic changes caused by tumor shrinkage during RT. In the study of Kanzaki et al. (28), higher tumor reduction rate (defined as 1-GTV at the assessment time during treatment $v s$. initial GTV), correlated with better OS in squamous cell lung cancer $(\mathrm{P}=0.013)$, and with worse OS in adenocarcinoma $(\mathrm{P}=0.03)$. Koo et al. (34), in the study including $55 \%$ squamous cell lung cancers, showed a trend for poorer OS in subjects with larger volume reduction ratio (VRR) $(\mathrm{HR}=1.89 ; \mathrm{P}=0.075)$. Likewise, in the study of Elsayad et al. (35), higher VRR after delivery of 40 Gy was predictive for poorer OS, particularly in nonadenocarcinoma patients. The authors hypothesized that high VRR may be indicative for more aggressive tumor behavior, as a fast response to CHRT is typical for small cell lung cancer.

Novel tools may facilitate objective tracking of tumor response during RT. Routinely used kilovoltage cone beam computed tomography ( $\mathrm{kV}$-CBCT) integrated into the linear accelerator, allows for on-line image guided RT. In the study of Wald et al. (36), greater reduction of GTV, sequentially assessed with kv-CBCT during the first four weeks of RT, was significantly associated with better distant control, PFS and OS. On the contrary, in the study of Kong et al. (37), mid-treatment decrease in MTV above mean was associated with shorter OS, but among patients who received mid-treatment $M T V$-adapted RT, OS was better in those with more than mean $v s$. less than mean MTV reduction (33 vs. 19 months, respectively). Interestingly, a recent study showed that higher tumor regression may be an adverse prognostic factor for CHRT, and a favorable prognostic factor for RT alone (38). Several studies have postulated the benefits of adaptive RT in locally advanced NSCLC (39-41). This approach is being investigated in the ongoing RTOG 1106 trial, results of which are expected shortly (42).

\section{Improvements of technique, dose and fractionation of radiotherapy}

Definitive RT has undergone significant progress, resulting in markedly improved therapeutic ratio. Increased biological effective dose (BED) with simultaneous protection of organs at risk (OAR) can be achieved with more precise definition of target volumes, use of conformal techniques, modification of dose and fractionation, and proper respiratory motion control.

\section{Techniques}

Historically, RT was planned using two-dimensional radiographs and bony landmarks with OAR protection by a cerrobend shielding. Imprecise visualization of target volumes required large RT fields to account for uncertainty, which resulted in noticeable toxicity. The advent of CT in the 1980s, and the widespread use of customized beam shaping with modern multileaf collimators (MLC), led to the development of three-dimensional conformal RT (3D-RT). This technique, which became the standard RT procedure in lung cancer, enables for precise and automatic beam shaping around a target volume and better shielding of OAR. 3D-RT also gives the opportunity to irradiate selectively involved lymph nodes with reduced target volumes. However, limited beam arrangements and uniform dose with this technique resulted in still high doses to OAR, especially in close proximity to the tumor.

The next, and one of the most important developments in RT techniques is intensity modulated RT (IMRT), which became commercially available in the beginning of 2000s. Its unique features include non-uniform intensity of the RT beams and computerized inverse planning. The beam modulation is provided through splitting a large RT field into small beamlets by the use of MLC with multiple narrow leafs moving during RT. Several beams build up a 
highly conformal dose distribution. Computer algorithm optimize the fluence map by iterative calculations and advanced algorithms to achieve the optimal plan. IMRT enables for dose escalation with high precision and can produce intentional dose inhomogeneity for multiple integrated targets with different dose prescriptions, e.g., to minimize dose to OAR or to deliver simultaneous integrated boost.

Important and clinically relevant improvement of dosimetry with IMRT was reported in several studies. IMRT can reduce percentage of lung volume exposed to the dose equal to 20 Gy or more (V20Gy) by $15 \%$, and esophageal V50Gy by $40 \%(43,44)$. There are no randomized studies comparing these two techniques in stage III NSCLC. However, numerous retrospective studies postulated clinical superiority of IMRT-based RT over conventional 3D-RT. In the study of Yom et al. (45), the incidence of grade 3 radiation pneumonitis at one year in stage III NSCLC patients who underwent CHRT with and without use of IMRT ( $\mathrm{n}=68$ and 222, respectively) was $8 \%$ vs. $32 \%$ respectively $(\mathrm{P}=0.002)$. Lower toxicity was achieved despite higher median GTV for IMRT plans (194 vs. $142 \mathrm{~mL}$ ), and was attributed to lower V20Gy. Other retrospective study comparing 4D/IMRT $v s$. conventional 3D-RT showed significantly lower toxicity and improved OS with the former (median OS of 1.4 vs. 0.85 years, respectively $\mathrm{P}=0.039$ ) (46). However, this improvement might have partly been due to stage migration, as more patients in the IMRT group were staged with ${ }^{18} \mathrm{~F}$-FDG PET-CT. Hu et al., 2016 (47) performed an overview of retrospective studies to assess conventional $3 \mathrm{D}-\mathrm{RT}$ and IMRT-based RT in terms of OS (five studies), radiation pneumonitis (four studies) and radiation esophagitis (four studies). OS with IMRT was improved in univariate, but not in multivariate analysis $(\mathrm{HR}=0.96 ; \mathrm{P}=0.477)$. The use of IMRT reduced the incidence of grade 2 radiation pneumonitis [relative risk (RR) of $0.74 ; \mathrm{P}=0.009$ ], but increased the incidence of grade 3 radiation esophagitis (RR $=2.47 ; \mathrm{P}<0.001)$.

In the RTOG 0617 phase III trial that explored two doses of definitive RT with or without cetuximab, the choice of RT technique was at the discretion of investigators, and the baseline characteristics in patients treated with or without IMRT were uneven (48). The group treated with IMRT had, compared to those treated with other techniques, larger average planning tumor volume (PTV) (409 vs. 509 $\mathrm{cm}^{3}$, respectively), higher PTV/lungs volume ratio, and included more stage IIIB cases ( $43 \%$ vs. 31\%, respectively).
Despite these imbalances, IMRT resulted in less pulmonary and heart toxicity, and in lower decline of quality of life (21\% vs. $46 \%$, respectively). There was no difference though in OS between IMRT and conventional 3D-RT.

Steeper dose gradients make IMRT strongly dependent on target and OAR volume specification and is therefore less forgiving for target volume inaccuracies than conventional 3D-RT. Routine use of IMRT and closely related techniques, such as volumetric arc RT, is thus particularly dependent on proper disease staging, accurate contouring, motion management, and image guidance with cone-beam CT, to avoid geographical miss.

\section{Involved field irradiation}

Involved-field RT (IFRT) denotes the delivery of RT only to areas apparently involved by a tumor. Several large retrospective studies demonstrated that in NSCLC the risk of isolated out-of-field nodal recurrence with IFRT is in the range of only 1-6\% (49-51). In the meta-analysis including three randomized clinical trials and three cohort studies, no significant difference was found in the incidence of elective nodal failure with the use of IFRT compared with ENI both in randomized trials ( $\mathrm{RR}=1.38,95 \%$ CI: 0.59-3.25; $\mathrm{P}=0.46)$, and in cohort studies ( $\mathrm{RR}=0.99,95 \% \mathrm{CI}: 0.46$ 2.10; $\mathrm{P}=0.97)(52)$.

Two randomized clinical trials showed that selective RT of involved lymph nodes in stage III NSCLC can increase OS, possibly by virtue of dose escalation. In the first trial 200 patients were randomized to receive either IFRT (68-74 Gy in 2 Gy fractions) or ENI (60-64 Gy in 2 Gy fractions) (53). Two and five-year OS rates were $39.4 \%$ and $25.1 \%$, respectively, with IFRT, and $25.6 \%$ and $18.3 \%$, respectively, with ENI (the difference in two-year OS rate was significant at $\mathrm{P}=0.048$ ). The limitations of this trial were single institution design and difference in RT doses between the arms. Other randomized trial compared IFRT (2.0 Gy daily for consecutive 5 days a week to the maximal tolerable dose) vs. maximal tolerable dose to GTV with the same fractionation, and ENI at a dose of 40-46 Gy (54). The median RT dose was 60 Gy (range, 38-74 Gy) in the IFRT arm, and 60 Gy (range, 32-70 Gy) in the ENI arm. More patients in the IFRT arm received at least 62 Gy $(48.9 \%$ vs. $25.9 \%$ in the ENI arm; $\mathrm{P}=0.018)$. Three-year OS rates for IFRT and ENI were $36.6 \%$ and $30.3 \%$, respectively $(\mathrm{P}=0.08)$. OS in patients who received at least $62 \mathrm{~Gy}$ in the IFRT arm was better than that in those administered doses below 62 Gy in both arms, and in those who received at 
least $62 \mathrm{~Gy}$ in the ENI arm $(\mathrm{P}=0.013)$. These results, and the results of the previously mentioned PET-Plan trial (15), confirm the efficacy of highly conformal IFRT with steep dose gradients.

\section{Dose and fractionation}

The landmark RTOG 7301 trial established the dose of 60 Gy in 2 Gy fractions as the standard for definitive RT in locally advanced NSCLC (55). Abundant radiobiology data suggest positive association between tumor BED and survival. The traditional approach is to escalate the total dose by increasing number of fractions. Preliminary singlearm dose escalation trials speculated that escalating dose over 60 Gy using 2 Gy fractions may provide some survival benefit. The RTOG 9311 study, which stratified patients to receive escalating doses of 3D-RT depending on V20 parameter, showed that dose can be safely increased to 83.8 Gy (56). In the RTOG 0117 phase I/II trial, maximum tolerated dose was 74 Gy in 37 fractions (57). In the pivotal RTOG 0617 study, however, patients who received higher conventionally fractionated RT dose (74 Gy) combined with concomitant CHT had surprisingly worse OS than those administered standard dose of $60 \mathrm{~Gy}$ (median OS of 20.3 and 28.7 months, respectively) (48). Higher dose was also associated with lower quality of life at three months, and higher incidence of severe esophagitis $(21 \%$ vs. $7 \%$ in the low-dose group). The most significant single factor for such a dramatic difference in favor of the 60 Gy appears to be radiation-induced toxicity, particularly cardiac toxicity in the high-dose arm. Additionally, concern regarding treatment toxicity may have prompted inappropriately tight radiation fields. Another aspect is repopulation during high-dose radiation given over 7.5 weeks. Hence, the dose escalation with a mere prolonging of overall treatment time of CHRT is clearly not the way to go to improve treatment outcomes.

High BED without prolonging overall treatment time can be delivered with altered fractionation (hyperfractionation, accelerated fractionation or hypofractionation). RADITUX, a Dutch phase II trial investigating the impact of cetuximab combined with CHRT in stage III NSCLC, used IMRT at a dose of $66 \mathrm{~Gy}$ in 24 fractions (2.75 Gy per fraction) combined with daily cisplatin at a dose of $6 \mathrm{mg} / \mathrm{m}^{2}$ (4). The trial used all modern diagnostic and staging techniques, including mandatory ${ }^{18} \mathrm{~F}$-FDG PET-CT, MR brain imaging and invasive endoscopic procedures. There was no benefit from the addition of cetuximab, but results in both arms were impressive (median OS above 30 months, five-year OS of $37 \%$ ). Another phase II trial showed feasibility of hypofractionated RT (55 Gy in 20 fractions, 2.75 Gy per fraction) with concurrent cisplatin and vinorelbine, with outcomes typical for stage III NSCLC (7). ${ }^{18} \mathrm{~F}-\mathrm{FDG}$ PET-CT was mandated in this study, but brain imaging and IMRT were not routinely used. The randomized CHARTWEL study of hyperfractionated accelerated weekend-less RT (60 Gy in 40 fractions within 2.5 weeks) vs. conventional RT (66 Gy in 33 fractions over 6.5 weeks) with or without induction CHT showed no benefit of the shortened schedule (58). Hitherto, there are no data from randomized studies to support altered fractionation RT schedules with concurrent CHT in stage III NSCLC. More thorough review of fractionation RT schedules in locally advanced NSCLC will be addressed in another article of this issue of Translational Lung Cancer Research.

\section{Motion management}

Respiration-induced tumor motion is a major obstacle for achieving a precise RT of lung cancer. The most significant movement is in cranio-caudal direction (59), and lower parts of the lungs show higher motion amplitudes (60). Small, compared to larger tumors, are more mobile (61). Successful delivery of highly conformal RT depends on individual information about tumor movements, which is obtained by four-dimensional CT (4D-CT), with external marker to correlate tumor motion with respiratory cycle. For most patients, single 4D-CT for treatment planning is sufficient (62). 4D-CT planning is also the basis for tumor motion management techniques, such as deep inspiration breath hold, respiration gating (switching on RT when the target is in desired phase/position) or tumor tracking (beam follows the fiducials within the target during entire respiratory cycle). Motion management for RT of stage III NSCLC is discussed in detail in another article of this issue of Translational Lung Cancer Research.

\section{Systemic therapy}

Concurrent, compared to sequential CHT and RT, improves long-term OS in stage III NSCLC patients by approximately $5 \%$, at the expense of increased toxicity, mainly acute esophagitis (16). This benefit is achieved through increased locoregional, but not systemic control. Currently, several CHT schedules are routinely employed in concomitant CHRT. Of those, two cycles of cisplatin- 
etoposide or platinum-vinorelbine given every three weeks are well established and have been most commonly used in clinical trials included in the 2010 meta-analysis (16). The PROCLAIM phase III trial randomized patients with nonsquamous stage III NSCLC to RT combined with either two cycles of concomitant cisplatin-etoposide followed by consolidation with platinum-based doublet, or concomitant cisplatin-pemetrexed followed by consolidation with pemetrexed (3). There was no OS or PFS difference between the study arms, but pemetrexed-based regimen was associated with lower incidence of grade 3-4 drug-related adverse events (64\% vs. $77 \%$, respectively), particularly grade 3-4 neutropenia (24.4\% vs. $44.5 \%)$. Owing to this difference and easier logistics (fewer drug administrations), cisplatin-pemetrexed is currently used routinely as a part of CHRT for stage III non-squamous NSCLC. Another CHT schedule, weekly carboplatin and paclitaxel, is widely used in North America, including recent RTOG 0617 trial (5). Whereas radiosensitizing properties of carboplatin $v s$. cisplatin are still debated, this schedule is convenient due to relatively limited toxicity, and may be used in more fragile patients. However, a Chinese phase III trial demonstrated non-significantly worse OS in patients who received weekly carboplatin-paclitaxel compared to two cycles of cisplatin-etoposide every three weeks (median OS of 20.7 and 23.3 months, respectively; $\mathrm{P}=0.095$ ) (63). Cisplatinetoposide regimen was associated with significantly higher risk of grade 3-4 neutropenia, whereas the risk of radiation pneumonitis was significantly higher with paclitaxelcarboplatin. Similar OS and lower hematologic toxicity of paclitaxel-carboplatin was also found in earlier retrospective analysis comparing these two regimens (64). Likewise, in the systematic review of published trials both regimens were similarly effective (median OS of 19.6 and 18.4 months for cisplatin-etoposide and paclitaxel-carboplatin, respectively) (65). Hematological toxicity was higher for cisplatin-etoposide, and there was no difference in pulmonary toxicity. Thus, weekly carboplatin-paclitaxel combined with concomitant RT remains a viable option, particularly in patients with other comorbidities and still adequate pulmonary reserve. An effective option is also, developed almost three decades ago and still used, daily cisplatin at $6 \mathrm{mg} / \mathrm{m}^{2}$ with concurrent hypofractionated RT (66 Gy in 24 fractions) (66).

Another approach to increase efficacy of CHRT is employing additional induction or consolidation systemic therapy (67). Studies using CHT before (68) or after CHRT (69-71) did not demonstrate improved outcomes, and showed increased toxicity with these approaches. Despite no clear benefit, consolidation docetaxel is still used in some centers, particularly after concurrent CHRT with weekly carboplatin-paclitaxel, with the rationale of inadequate systemic exposure with this regimen.

Likewise, no benefit was found with adjunctive targeted therapies. In the SWOG 0023 trial patients who completed CHRT and consolidation docetaxel were randomly assigned to gefitinib $250 \mathrm{mg}$ daily or placebo (72). Surprisingly, the addition of gefitinib resulted in shorter OS compared to placebo (median OS of 23 and 35 months, respectively; $\mathrm{P}=0.013)$. In the previously mentioned RTOG 0617 study, that compared two doses of RT, patients were additionally assigned to cetuximab or placebo concurrently with CHRT and as consolidation. There was no benefit from EGFR blockade (median OS 25 and 24 months in cetuximab and placebo arms, respectively; $\mathrm{P}=0.58$ ), whereas grade 3 or greater toxicity was higher in the former $(86 \% v s .70 \%$, respectively) (48). The development of consolidation bevacizumab was terminated due excessive toxicity of this approach (73).

Currently, the only consolidation approach providing an apparent clinical benefit remains durvalumab, an antiPD-L1 monoclonal antibody (10).

\section{Chemoradiation in elderly patients}

Most patients diagnosed with NSCLC are 65 or older, and the population of elderly people will continue to increase. Lung cancer patients have also multiple comorbidities and may not be amenable for aggressive therapeutic approaches such as CHRT. In a consecutive series of De Ruysscher et al. (74), the proportion of serious comorbidities in patients below and above 75 years was $47 \%$ and $63 \%$, respectively. The eligibility rate for CHRT was $50 \%$ in the age group of $60-69,41 \%$ in the age group of 70 74 years, and $0 \%$ in patients 75 years or older. Elderly patients have been poorly represented in controlled clinical trials of locally advanced NSCLC. The only randomized study designed for elderly patients with unresectable locally advanced NSCLC was terminated prematurely due to excessive toxicity (75).

Retrospective and subgroup analyses of randomized trials indicate that CHRT can still be an option for selected elderly patients. The RTOG 94-10 phase III trial compared sequential CHRT (induction cisplatin plus vinblastine followed by RT on day 50, SEQ) vs. two concurrent regimens: (cisplatin plus vinorelbine combined with $60 \mathrm{~Gy}$ 
(CON-QD), or cisplatin plus etoposide combined with twice daily RT for a total dose of $69.6 \mathrm{~Gy}$ (CON-BID). Of the 610 patients enrolled, only $17 \%$ were 70 years or older. The median OS in the elderly subset was 22.4 months for CON-QD and 16.4 months for CON-BID, vs. 10.8 months for SEQ ( $\mathrm{P}=0.069)$, whereas there was no notable difference in the younger group (median OS of 15.5, 16.0 and 15.7 months, respectively. However, the incidence of severe esophagitis with concomitant approach in elderly was higher (33\% and $60 \%$, for QD and BID, respectively) than in patients below 70 years (23\% and $42 \%$, respectively). Long-term toxicities were similar in both age groups (76).

In the randomized NCCTG trial 5-year survival rates with CHRT were $13 \%$ in patients aged 70 years or older $v s .18 \%$ in those below 70 years $(\mathrm{P}=0.4)$. Despite increased toxicity, elderly patients have survival rates equivalent to younger individuals (77). In the metaanalysis by Auperin et al. (16) the advantage of concomitant over sequential CHRT included also patients older than 70 years.

Data from the National Cancer Database indicate that CHRT (be sequential or concurrent) in elderly patients is more effective than RT alone, however sequential CHRT was superior to concurrent CHRT (HR $=0.91,95 \%$ CI: 0.85-0.96, $\mathrm{P}=0.002)(78)$.

On the other hand, pooled analysis of six RTOG studies showed that the best quality of life-adjusted survival in patients $>70$ years of age was observed with RT alone (79).

An ongoing PACIFIC 6 study investigates an option of sequential CRT followed by immunotherapy, which may be particularly relevant in the older population of patients (ClinicalTrials.gov identifier NCT03693300).

The EORTC Elderly Task Force and Lung Cancer Group, and International Society for Geriatric Oncology, recommend that treatment decisions should be based on patient characteristic and fit senior patients could benefit from concurrent CHRT (80). Clearly, a thorough patient selection including geriatric assessment may allow treatment optimization in this group of patients.

\section{Conclusions and future directions}

For almost two decades CHRT has constituted a therapeutic standard in locally advanced inoperable NSCLC. Compared to the results of the meta-analysis published 10 years ago (16), the efficacy of definitive CHRT for stage III NSCLC has markedly improved. A median OS of approximately 20-30 months, and five- year OS of approximately $30 \%$, without consolidation immunotherapy, has been achieved. This progress has been predominantly due to improved staging, advanced RT technologies and restrictive quality control, and less due to more effective CHT. Indeed, local and regional control with CHRT is currently in the range of $80 \%$ and $90 \%$, respectively (81), leaving a narrow margin for further improvement. On the other hand, around $40-50 \%$ of patients will relapse at distant sites, therefore increasing cure rate will necessitate more effective systemic therapies. A recent spectacular example of such approach is consolidation immunotherapy after definitive CHRT (10), the current therapeutic standard in inoperable stage III NSCLC.

\section{Acknowledgments}

Funding: None.

\section{Footnote}

Provenance and Peer Review: This article was commissioned by the editorial office, Translational Lung Cancer Research for the series "Radiotherapy in thoracic malignancies. The article has undergone external peer review.

Reporting Checklist: The authors have completed the Narrative Review reporting checklist. Available at http:// dx.doi.org/10.21037/tlcr-20-704

Peer Review File: Available at http://dx.doi.org/10.21037/ tlcr-20-704

Conflicts of Interest: All authors have completed the ICMJE uniform disclosure form (available at http://dx.doi. org/10.21037/tlcr-20-704). The series "Radiotherapy in thoracic malignancies" was commissioned by the editorial office without any funding or sponsorship. RD served as the unpaid Guest Editor of the series. JJ served as the unpaid Guest Editor of the series and serves as an unpaid editorial board member of Translational Lung Cancer Research from Sep 2019 to Sep 2021. RD reports personal fees and other from Roche, personal fees and other from AstraZeneca, personal fees from Novartis, personal fees from Pfizer, personal fees from MSD, personal fees from Takeda, personal fees from Boehringer-Ingelheim, personal fees from Foundation Medicine, outside the submitted work. JJ reports Speaker: AstraZeneca, Roche, Pfizer; Advisory 
roles: AstraZeneca, BMS, Pfizer, MSD, Takeda; Travel support: Roche, Pfizer. The authors have no other conflicts of interest to declare.

Ethical Statement: The authors are accountable for all aspects of the work in ensuring that questions related to the accuracy or integrity of any part of the work are appropriately investigated and resolved.

Open Access Statement: This is an Open Access article distributed in accordance with the Creative Commons Attribution-NonCommercial-NoDerivs 4.0 International License (CC BY-NC-ND 4.0), which permits the noncommercial replication and distribution of the article with the strict proviso that no changes or edits are made and the original work is properly cited (including links to both the formal publication through the relevant DOI and the license). See: https://creativecommons.org/licenses/by-nc-nd/4.0/.

\section{References}

1. Goldstraw P, Chansky K, Crowley J, et al. The IASLC Lung Cancer Staging Project: Proposals for Revision of the TNM Stage Groupings in the Forthcoming (Eighth) Edition of the TNM Classification for Lung Cancer. J Thorac Oncol 2016;11:39-51.

2. Huber RM, De Ruysscher D, Hoffmann H, et al. Interdisciplinary multimodality management of stage III nonsmall cell lung cancer. Eur Respir Rev 2019;28:190024.

3. Senan S, Brade A, Wang LH, et al. PROCLAIM: Randomized Phase III Trial of Pemetrexed-Cisplatin or Etoposide-Cisplatin Plus Thoracic Radiation Therapy Followed by Consolidation Chemotherapy in Locally Advanced Nonsquamous Non-Small-Cell Lung Cancer. J Clin Oncol 2016;34:953-62.

4. Walraven I, van den Heuvel M, van Diessen J, et al. Longterm follow-up of patients with locally advanced non-small cell lung cancer receiving concurrent hypofractionated chemoradiotherapy with or without cetuximab. Radiother Oncol 2016;118:442-6.

5. Bradley JD, Hu C, Komaki RR, et al. Long-Term Results of NRG Oncology RTOG 0617: Standard- Versus HighDose Chemoradiotherapy With or Without Cetuximab for Unresectable Stage III Non-Small-Cell Lung Cancer. J Clin Oncol 2020;38:706-14.

6. Fleckenstein J, Hellwig D, Kremp S, et al. F-18-FDG-PET confined radiotherapy of locally advanced NSCLC with concomitant chemotherapy: results of the PET-PLAN pilot trial. Int J Radiat Oncol Biol Phys 2011;81:e283-9.

7. Maguire J, Khan I, McMenemin R, et al. SOCCAR: A randomised phase II trial comparing sequential versus concurrent chemotherapy and radical hypofractionated radiotherapy in patients with inoperable stage III NonSmall Cell Lung Cancer and good performance status. Eur J Cancer 2014;50:2939-49.

8. Butts C, Socinski MA, Mitchell PL, et al. Tecemotide (L-BLP25) versus placebo after chemoradiotherapy for stage III non-small-cell lung cancer (START): a randomised, double-blind, phase 3 trial. Lancet Oncol 2014;15:59-68.

9. Flentje M, Huber RM, Engel-Riedel W, et al. GILT-A randomised phase III study of oral vinorelbine and cisplatin with concomitant radiotherapy followed by either consolidation therapy with oral vinorelbine and cisplatin or best supportive care alone in stage III non-small cell lung cancer. Strahlenther Onkol 2016;192:216-22.

10. Antonia SJ, Villegas A, Daniel D, et al. Durvalumab after Chemoradiotherapy in Stage III Non-Small-Cell Lung Cancer. N Engl J Med 2017;377:1919-29.

11. Eberhardt WE, De Ruysscher D, Weder W, et al. 2nd ESMO Consensus Conference in Lung Cancer: locally advanced stage III non-small-cell lung cancer. Ann Oncol 2015;26:1573-88.

12. Nestle U, De Ruysscher D, Ricardi U, et al. ESTRO ACROP guidelines for target volume definition in the treatment of locally advanced non-small cell lung cancer. Radiother Oncol 2018;127:1-5.

13. Kligerman S, Digumarthy S. Staging of Non-Small Cell Lung Cancer Using Integrated PET/CT. AJR Am J Roentgenol 2009;193:1203-11.

14. Gould MK, Kuschner WG, Rydzak CE, et al. Test performance of positron emission tomography and computed tomography for mediastinal staging in patients with non-small-cell lung cancer: a meta-analysis. Ann Intern Med 2003;139:879-92.

15. Nestle U, Schimek-Jasch T, Kremp S, et al. Imagingbased target volume reduction in chemoradiotherapy for locally advanced non-small-cell lung cancer (PET-Plan): a multicentre, open-label, randomised, controlled trial. Lancet Oncol 2020;21:581-92.

16. Aupérin A, Le Péchoux C, Rolland E, et al. Meta-analysis of concomitant versus sequential radiochemotherapy in locally advanced non-small-cell lung cancer. J Clin Oncol 2010;28:2181-90.

17. Vokes EE, Govindan R, Iscoe N, et al. The Impact of Staging by Positron-Emission Tomography on Overall 
Survival and Progression-Free Survival in Patients With Locally Advanced NSCLC. J Thorac Oncol 2018;13:1183-8.

18. Yang B, Lee H, Um SW, et al. Incidence of brain metastasis in lung adenocarcinoma at initial diagnosis on the basis of stage and genetic alterations. Lung Cancer 2019;129:28-34.

19. Waqar SN, Samson PP, Robinson CG, et al. Non-smallcell Lung Cancer With Brain Metastasis at Presentation. Clin Lung Cancer 2018;19:e373-9.

20. Schoenmaekers J, Hofman P, Bootsma G, et al. Screening for brain metastases in patients with stage III nonsmall-cell lung cancer, magnetic resonance imaging or computed tomography? A prospective study. Eur J Cancer 2019;115:88-96.

21. Peeters ST, Dooms C, Van Baardwijk A, et al. Selective mediastinal node irradiation in non-small cell lung cancer in the IMRT/VMAT era: How to use E(B)USNA information in addition to PET-CT for delineation? Radiother Oncol 2016;120:273-8.

22. Brenner DJ. Dose, volume, and tumor-control predictions in radiotherapy. Int J Radiat Oncol Biol Phys 1993;26:171-9.

23. Abratt RP. Modeling tumor and treated lung volume influences in the irradiation of non-small-cell lung cancer patients. Int J Radiat Oncol Biol Phys 2001;49:481-5.

24. Alexander BM, Othus M, Caglar HB, et al. Tumor volume is a prognostic factor in non-small-cell lung cancer treated with chemoradiotherapy. Int J Radiat Oncol Biol Phys 2011;79:1381-7.

25. Käsmann L, Niyazi M, Blanck O, et al. Predictive and prognostic value of tumor volume and its changes during radical radiotherapy of stage III non-small cell lung cancer: A systematic review. Strahlenther Onkol 2018;194:79-90.

26. Bradley JD, Ieumwananonthachai N, Purdy JA, et al. Gross tumor volume, critical prognostic factor in patients treated with three-dimensional conformal radiation therapy for non-small-cell lung carcinoma. Int J Radiat Oncol Biol Phys 2002;52:49-57.

27. Ball DL, Fisher RJ, Burmeister BH, et al. The complex relationship between lung tumor volume and survival in patients with non-small cell lung cancer treated by definitive radiotherapy: a prospective, observational prognostic factor study of the Trans-Tasman Radiation Oncology Group (TROG 99.05). Radiother Oncol 2013;106:305-11.

28. Kanzaki H, Kataoka M, Nishikawa A, et al. Impact of early tumor reduction on outcome differs by histological subtype in stage III non-small-cell lung cancer treated with definitive radiotherapy. Int J Clin Oncol 2016;21:853-61.

29. Brodin NP, Tomé WA, Abraham T, et al. (18)

F-Fluorodeoxyglucose PET in Locally Advanced Nonsmall Cell Lung Cancer: From Predicting Outcomes to Guiding Therapy. PET Clin 2020;15:55-63.

30. Ohri N, Duan F, Machtay M, et al. Pretreatment FDG-PET metrics in stage III non-small cell lung cancer: ACRIN 6668/RTOG 0235. J Natl Cancer Inst 2015;107:djv004.

31. Ohri N, Piperdi B, Garg MK, et al. Pre-treatment FDGPET predicts the site of in-field progression following concurrent chemoradiotherapy for stage III non-small cell lung cancer. Lung Cancer 2015;87:23-7.

32. Ercelep O, Alan O, Sahin D, et al. Effect of PET/ CT standardized uptake values on complete response to treatment before definitive chemoradiotherapy in stage III non-small cell lung cancer. Clin Transl Oncol 2019;21:499-504.

33. Lee VH, Chan WW, Lee EY, et al. Prognostic Significance of Standardized Uptake Value of Lymph Nodes on Survival for Stage III Non-small Cell Lung Cancer Treated With Definitive Concurrent Chemoradiotherapy. Am J Clin Oncol 2016;39:355-62.

34. Koo TR, Moon SH, Lim YJ, et al. The effect of tumor volume and its change on survival in stage III nonsmall cell lung cancer treated with definitive concurrent chemoradiotherapy. Radiat Oncol 2014;9:283.

35. Elsayad K, Samhouri L, Scobioala S, et al. Is tumor volume reduction during radiotherapy prognostic relevant in patients with stage III non-small cell lung cancer? J Cancer Res Clin Oncol 2018;144:1165-71.

36. Wald P, Mo X, Barney C, et al. Prognostic Value of Primary Tumor Volume Changes on kV-CBCT during Definitive Chemoradiotherapy for Stage III Non-Small Cell Lung Cancer. J Thorac Oncol 2017;12:1779-87.

37. Kong FS, Li L, Wang W, et al. Greater reduction in midtreatment FDG-PET volume may be associated with worse survival in non-small cell lung cancer. Radiother Oncol 2019;132:241-9.

38. van Timmeren JE, van Elmpt W, de Ruysscher D, et al. Tumor regression during radiotherapy for non-small cell lung cancer patients using cone-beam computed tomography images. Strahlenther Onkol 2020;196:159-71.

39. Woodford C, Yartsev S, Dar AR, et al. Adaptive radiotherapy planning on decreasing gross tumor volumes as seen on megavoltage computed tomography images. Int J Radiat Oncol Biol Phys 2007;69:1316-22. 
40. Chen M, Yang J, Liao Z, et al. Anatomic change over the course of treatment for non-small cell lung cancer patients and its impact on intensity-modulated radiation therapy and passive-scattering proton therapy deliveries. Radiat Oncol 2020;15:55.

41. Yuan Z, Rong Y, Benedict SH, et al. "Dose of the day" based on cone beam computed tomography and deformable image registration for lung cancer radiotherapy. J Appl Clin Med Phys 2020;21:88-94.

42. Kong FM, Ten Haken RK, Schipper M, et al. Effect of Midtreatment PET/CT-Adapted Radiation Therapy With Concurrent Chemotherapy in Patients With Locally Advanced Non-Small-Cell Lung Cancer: A Phase 2 Clinical Trial. JAMA Oncol 2017;3:1358-65.

43. Grills IS, Yan D, Martinez AA, et al. Potential for reduced toxicity and dose escalation in the treatment of inoperable non-small-cell lung cancer: a comparison of intensitymodulated radiation therapy (IMRT), 3D conformal radiation, and elective nodal irradiation. Int J Radiat Oncol Biol Phys 2003;57:875-90.

44. Christian JA, Bedford JL, Webb S, et al. Comparison of inverse-planned three-dimensional conformal radiotherapy and intensity-modulated radiotherapy for non-small-cell lung cancer. Int J Radiat Oncol Biol Phys 2007;67:735-41.

45. Yom SS, Liao Z, Liu HH, et al. Initial evaluation of treatment-related pneumonitis in advanced-stage nonsmall-cell lung cancer patients treated with concurrent chemotherapy and intensity-modulated radiotherapy. Int J Radiat Oncol Biol Phys 2007;68:94-102.

46. Liao ZX, Komaki RR, Thames HD Jr, et al. Influence of technologic advances on outcomes in patients with unresectable, locally advanced non-small-cell lung cancer receiving concomitant chemoradiotherapy. Int J Radiat Oncol Biol Phys 2010;76:775-81.

47. Hu X, He W, Wen S, et al. Is IMRT Superior or Inferior to 3DCRT in Radiotherapy for NSCLC? A Meta-Analysis. PLoS One 2016;11:e0151988.

48. Bradley JD, Paulus R, Komaki R, et al. Standarddose versus high-dose conformal radiotherapy with concurrent and consolidation carboplatin plus paclitaxel with or without cetuximab for patients with stage IIIA or IIIB non-small-cell lung cancer (RTOG 0617): a randomised, two-by-two factorial phase 3 study. Lancet Oncol 2015;16:187-99.

49. Rosenzweig KE, Sura S, Jackson A, et al. Involved-field radiation therapy for inoperable non small-cell lung cancer. J Clin Oncol 2007;25:5557-61.

50. Sulman EP, Komaki R, Klopp AH, et al. Exclusion of elective nodal irradiation is associated with minimal elective nodal failure in non-small cell lung cancer. Radiat Oncol 2009;4:5.

51. Martinussen HM, Reymen B, Wanders R, et al. Is selective nodal irradiation in non-small cell lung cancer still safe when using IMRT? Results of a prospective cohort study. Radiother Oncol 2016;121:322-7.

52. Li R, Yu L, Lin S, et al. Involved field radiotherapy (IFRT) versus elective nodal irradiation (ENI) for locally advanced non-small cell lung cancer: a meta-analysis of incidence of elective nodal failure (ENF). Radiat Oncol 2016;11:124.

53. Yuan S, Sun X, Li M, et al. A randomized study of involved-field irradiation versus elective nodal irradiation in combination with concurrent chemotherapy for inoperable stage III non small cell lung cancer. Am J Clin Oncol 2007;30:239-44.

54. Chen M, Bao Y, Ma HL, et al. Involved-field radiotherapy versus elective nodal irradiation in combination with concurrent chemotherapy for locally advanced non-small cell lung cancer: a prospective randomized study. Biomed Res Int 2013;2013:371819.

55. Perez CA, Stanley K, Rubin P, et al. A prospective randomized study of various irradiation doses and fractionation schedules in the treatment of inoperable non-oat-cell carcinoma of the lung. Preliminary report by the Radiation Therapy Oncology Group. Cancer 1980;45:2744-53.

56. Bradley J, Graham MV, Winter K, et al. Toxicity and outcome results of RTOG 9311: a phase I-II doseescalation study using three-dimensional conformal radiotherapy in patients with inoperable non-smallcell lung carcinoma. Int J Radiat Oncol Biol Phys 2005;61:318-28.

57. Bradley JD, Moughan J, Graham MV, et al. A phase I/II radiation dose escalation study with concurrent chemotherapy for patients with inoperable stages I to III non-small-cell lung cancer: phase I results of RTOG 0117. Int J Radiat Oncol Biol Phys 2010;77:367-72.

58. Baumann M, Herrmann T, Koch R, et al. Final results of the randomized phase III CHARTWEL-trial (ARO 97-1) comparing hyperfractionated-accelerated versus conventionally fractionated radiotherapy in non-small cell lung cancer (NSCLC). Radiother Oncol 2011;100:76-85.

59. Michalski D, Sontag M, Li F, et al. Four-dimensional computed tomography-based interfractional reproducibility study of lung tumor intrafractional motion. Int J Radiat Oncol Biol Phys 2008;71:714-24.

60. Knybel L, Cvek J, Molenda L, et al. Analysis of Lung 
Tumor Motion in a Large Sample: Patterns and Factors Influencing Precise Delineation of Internal Target Volume. Int J Radiat Oncol Biol Phys 2016;96:751-8.

61. Liu HH, Balter P, Tutt T, et al. Assessing respirationinduced tumor motion and internal target volume using four-dimensional computed tomography for radiotherapy of lung cancer. Int J Radiat Oncol Biol Phys 2007;68:531-40.

62. Redmond KJ, Song DY, Fox JL, et al. Respiratory motion changes of lung tumors over the course of radiation therapy based on respiration-correlated four-dimensional computed tomography scans. Int J Radiat Oncol Biol Phys 2009;75:1605-12.

63. Liang J, Bi N, Wu S, et al. Etoposide and cisplatin versus paclitaxel and carboplatin with concurrent thoracic radiotherapy in unresectable stage III non-small cell lung cancer: a multicenter randomized phase III trial. Ann Oncol 2017;28:777-83.

64. Liew MS, Sia J, Starmans MH, et al. Comparison of toxicity and outcomes of concurrent radiotherapy with carboplatin/paclitaxel or cisplatin/etoposide in stage III non-small cell lung cancer. Cancer Med 2013;2:916-24.

65. Steuer CE, Behera M, Ernani V, et al. Comparison of Concurrent Use of Thoracic Radiation With Either Carboplatin-Paclitaxel or Cisplatin-Etoposide for Patients With Stage III Non-Small-Cell Lung Cancer: A Systematic Review. JAMA Oncol 2017;3:1120-9.

66. Schaake-Koning C, van den Bogaert W, Dalesio O, et al. Effects of Concomitant Cisplatin and Radiotherapy on Inoperable Non-Small-Cell Lung Cancer. New Engl J Med 1992;326:524-30.

67. Skrzypski M, Jassem J. Consolidation systemic treatment after radiochemotherapy for unresectable stage III nonsmall cell lung cancer. Cancer Treat Rev 2018;66:114-21.

68. Vokes EE, Herndon JE, 2nd, Kelley MJ, et al. Induction chemotherapy followed by chemoradiotherapy compared with chemoradiotherapy alone for regionally advanced unresectable stage III Non-small-cell lung cancer: Cancer and Leukemia Group B. J Clin Oncol 2007;25:1698-704.

69. Jalal SI, Riggs HD, Melnyk A, et al. Updated survival and outcomes for older adults with inoperable stage III nonsmall-cell lung cancer treated with cisplatin, etoposide, and concurrent chest radiation with or without consolidation docetaxel: analysis of a phase III trial from the Hoosier Oncology Group (HOG) and US Oncology. Ann Oncol 2012;23:1730-8.

70. Ahn JS, Ahn YC, Kim JH, et al. Multinational Randomized Phase III Trial With or Without Consolidation
Chemotherapy Using Docetaxel and Cisplatin After Concurrent Chemoradiation in Inoperable Stage III NonSmall-Cell Lung Cancer: KCSG-LU05-04. J Clin Oncol 2015;33:2660-6.

71. Tsujino K, Kurata T, Yamamoto S, et al. Is consolidation chemotherapy after concurrent chemo-radiotherapy beneficial for patients with locally advanced non-small-cell lung cancer? A pooled analysis of the literature. J Thorac Oncol 2013;8:1181-9.

72. Kelly K, Chansky K, Gaspar LE, et al. Phase III trial of maintenance gefitinib or placebo after concurrent chemoradiotherapy and docetaxel consolidation in inoperable stage III non-small-cell lung cancer: SWOG S0023. J Clin Oncol 2008;26:2450-6.

73. Wozniak AJ, Moon J, Thomas CR, Jr, et al. A Pilot Trial of Cisplatin/Etoposide/Radiotherapy Followed by Consolidation Docetaxel and the Combination of Bevacizumab (NSC-704865) in Patients With Inoperable Locally Advanced Stage III Non-Small-Cell Lung Cancer: SWOG S0533. Clin Lung Cancer 2015;16:340-7.

74. De Ruysscher D, Botterweck A, Dirx M, et al. Eligibility for concurrent chemotherapy and radiotherapy of locally advanced lung cancer patients: a prospective, populationbased study. Ann Oncol 2009;20:98-102.

75. Atagi S. Kawahara M, Tamura T, et al. Standard thoracic radiotherapy with or without concurrent daily low-dose carboplatin in elderly patients with locally advanced non-small cell lung cancer: a Phase III trial of the Japan Clinical Oncology Group (JCOG9812). Jpn J Clin Oncol 2005;35:195-201.

76. Langer CJ, Hsu C, Curran W. et al. Elderly patients (pts) with locally advanced non-small cell lung cancer (LA-NSCLC) benefit from combined modality therapy: secondary analysis of Radiation Therapy Oncology Group (RTOG) 94-10. Proc Am Soc Clin Oncol 2002;21:abstr 1193.

77. Schild SE, Stella PJ, Geyer SM et al. The outcome of combined-modality therapy for stage III non-small-cell lung cancer in the elderly. J Clin Oncol 2003;21:3201-6.

78. Miller ED, Fisher JL, Haglund KE, et al. The Addition of Chemotherapy to Radiation Therapy Improves Survival in Elderly Patients with Stage III Non-Small Cell Lung Cancer. J Thorac Oncol 2018;13:426-35.

79. Movsas B, Scott C, Sause W et al. The benefit of treatment intensification is age and histology-dependent in patients with locally advanced non-small cell lung cancer (NSCLC): a quality-adjusted survival analysis of radiation therapy oncology group (RTOG) chemoradiation studies. 
Int J Radiat Oncol Biol Phys 1999;45:1143-9.

80. Pallis AG, Gridelli C, van Meerbeeck JP, et al. EORTC Elderly Task Force and Lung Cancer Group and International Society for Geriatric Oncology (SIOG) experts' opinion for the treatment of non-small cell lung cancer in an elderly population. Ann Oncol

Cite this article as: Łazar-Poniatowska M, Bandura A, Dziadziuszko R, Jassem J. Concurrent chemoradiotherapy for stage III non-small-cell lung cancer: recent progress and future perspectives (a narrative review). Transl Lung Cancer Res 2021;10(4):2018-2031. doi: 10.21037/tlcr-20-704
2010;21:692-706.

81. van Diessen JN, Chen C, van den Heuvel MM, et al. Differential analysis of local and regional failure in locally advanced non-small cell lung cancer patients treated with concurrent chemoradiotherapy. Radiother Oncol 2016;118:447-52. 